\title{
La relatividad de los derechos subjetivos de los consumidores
}

\author{
Erika Isler Soto*
}

\section{RESUMEN}

El presente trabajo intenta realizar una aproximación al abuso del derecho, desde la perspectiva de los derechos de los consumidores. En razón de lo anterior, comienza con una breve exposición de lo que se entiende precisamente por la institución referida, para posteriormente analizar la naturaleza de las garantías establecidas en la Ley $N^{\circ} 19.496$. Con posterioridad, se proponen algunas limitaciones que en nuestro ordenamiento jurídico restringen las garantías de los usuarios, y cuya vulneración daría origen a un ejercicio abusivo de los derechos.

Abuso del derecho - consumidor - derecho subjetivo

\section{The relativity of the subjective rights of consumers}

\begin{abstract}
This work attempts to approach the abuse of rights, from the perspective of the rights of consumers. To achieve this objective, it begins with a brief statement of what precisely is meant by the referred institution. Subsequently, it analyses the nature of the warranty established in the Act 19,496. Consequently, it is suggested that some limitations in our legal system restrict the warranties of users, and whose violation would lead to an abusive exercise of rights.
\end{abstract}

Abuse of right - consumer - subjective right

* Abogada, Magíster en Derecho, Diploma en Género y Políticas Públicas, Servicio Nacional de la Mujer; Diploma de Especialización en Derechos Humanos, Pedagogía de la Memoria y Políticas Culturales, Fundación Henry Dunant; Profesora Facultad de Derecho y Comunicación Social, Universidad Bernardo O’Higgins, Santiago de Chile. erikaisler@yahoo.es

Artículo recibido el 5 de junio de 2011 y aceptado para su publicación por el Comité Editorial el 28 de octubre de 2011. 


\section{INTRODUCCIÓN ${ }^{1}$}

$\mathrm{E}$ 1 abuso del derecho no genera consenso. En efecto, si bien en la primera época de la codificación fue ignorado -en razón de las ideas liberales imperantes en ese entonces- con posterioridad no pocos cuerpos normativos optaron por reconocerlo expresamente, sea aceptándolo o rechazándolo ${ }^{2}$. Asimismo, y tal como lo explica Fernández Sessarego, son muchos los estatutos que lo recogen de manera indirecta o a través de otras instituciones que lo manifiestan ${ }^{3}$.

En cualquier caso, se trata de una doctrina que en su origen constituyó una reivindicación social, surgida como reacción al liberalismo político y jurídico, y que conllevó incluso una nueva concepción de los derechos subjetivos ${ }^{4}$. De esta manera, la tesis del abuso del derecho siguió el mismo camino que debieron recorrer las garantías de los consumidores, hasta lograr su consagración.

Ahora bien, en nuestro ordenamiento jurídico la noción y tratamiento de la institución en estudio carece de una regulación orgánica, sin perjuicio de que es posible reconocer sus manifestaciones en algunas normas dispersas ${ }^{5}$. En este sentido, señala Fueyo que ni nuestro Código Civil ni sus leyes modificatorias utilizan la voz "abuso del derecho", no obstante acogerlo como principio: se trataría pues de un fenómeno recogido mas nunca nombrado ${ }^{6}$.

La legislación chilena protectora de los derechos de los consumidores no es la excepción. En efecto, si difícilmente es posible hablar de una normativa del consumo

${ }^{1}$ Abreviaturas utilizadas: Art.: artículo; C.C.: Código Civil; C. Ap.: Corte de Apelaciones; C.S.: Corte Suprema; Cfr.: Confrontar; CPR: Constitución Política de la República; Ing.: Ingreso de Corte; LPC: Ley No 19.496; op. cit.: Obra citada; RAE: Real Academia de la Lengua Española.

${ }^{2}$ El primer ordenamiento jurídico que se refirió expresamente al principio del abuso del derecho fue el Landrecht de Prusia de 1794, en sus Art. 34-39: "No se debe indemnizar por un daño causado en el ejercicio de un derecho, a menos que entre las varias formas posibles de ejercerlo, se haya elegido aquella más dañosa a otro con el fin de ocasionarle perjuicio". Cfr. Terrazas Ponce, Juan David, "Abuso del derecho. Definiciones en torno a su origen”, en "Estudios de Derecho Privado. Libro homenaje al jurista René Abeliuk Manasevich”, Editorial Jurídica de Chile, Santiago, 2010, p. 281. Hoy en día se encuentra consagrado en otros cuerpos normativos, tales como: Art. II C.C. Perú; Art. 7 C.C. España; Art. 2 C.C. Suiza; Art. 95 Constitución Política de Colombia; Art. 830 C. Co. Colombia.

${ }^{3}$ Fernández Sessarego, Carlos, “Abuso del derecho”, Editorial Astrea, Buenos Aires, 1992, p. 2.

${ }^{4}$ Fernández Sessarego, Carlos, op. cit., p. 3: "La teoría del abuso del derecho surge, así, como una lógica reacción frente a los códigos civiles que, inspirados en la filosofía del Código Civil francés de 1804, trasuntan una posición de corte netamente individualista. Por todo ello, el abuso del derecho representa, en la actualidad, un instituto indispensable para la convivencia bumana, de suma importancia para edificar una sociedad más justa, solidaria y segura". Según Fueyo, además coincide con el desarrollo de la escuela sociológica del derecho: Fueyo Laneri, Fernando, "El ejercicio abusivo del derecho", en Revista del Colegio de Abogados, La Plata, 1988, p. 23.

${ }^{5}$ Del Código Civil: Arts. 945 (hoy suprimido, pasando a integrar el Art. 56 del Código de Aguas), 197, 328, 2108; $2110 ; 2111$ y 2112 C.C.; Otras normas: Art. 280 CPC; Art. 100 C. Co.; Art. 75 LGB; Art. 79 Ley de Sociedades Anónimas; Art. 48 Ley de Copropiedad Inmobiliaria; Art. 45 Ley de quiebras; Cfr. Terrazas Ponce, Juan David, op. cit., p. 281, y Fueyo Laneri, Fernando, "El ejercicio abusivo del derecho”, pp. 19 y 20.

${ }^{6}$ Fueyo Laneri, Fernando, "El ejercicio abusivo del derecho", p. 19. 
ordenada, integral y sistemática, más dificultoso aún resulta sostener que la Ley Nº 19.496 establece una teoría -ni siquiera particular- sobre el abuso del derecho.

No obstante lo anterior, lo que sí resulta claro es que la LPC confiere garantías al sujeto más débil de la relación de consumo. Surge entonces la pregunta acerca de si este último puede ejercer tales prerrogativas de manera ilimitada o si, por el contrario, contempla nuestro ordenamiento jurídico algunas restricciones para ello, y que una vez vulneradas pudiesen configurar supuestos de ejercicios abusivos de los derechos.

El presente trabajo pretende proponer una respuesta a la interrogante planteada, sugiriendo algunas líneas de pensamiento. Para ello, primeramente contempla una breve exposición de la teoría del abuso del derecho, con los conceptos únicamente necesarios para entender las consideraciones siguientes. Con posterioridad continúa con el análisis de la naturaleza jurídica de los derechos de los consumidores, para proseguir con las limitaciones y restricciones a su ejercicio. Finalmente se señalan algunas conclusiones.

\section{BREVE APRoXimación AL ABUSO DEL DERECHO}

Según Rotondi, se entiende por abuso al "uso malicioso", "reprobado y reprobable" o "ilegítimo" de un derecho por parte de quien es su titular". La RAE, por su lado, define al abuso del derecho simplemente como el "ejercicio de un derecho en sentido contrario a su finalidad

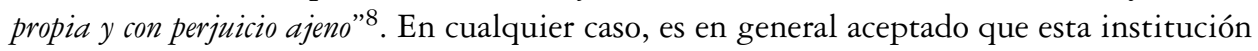
viene a introducir un elemento moralizante, en virtud del cual se quiere lograr la justicia cuando se ha perdido el equilibrio de las prestaciones, lo cual presenta particular importancia en los contratos onerosos ${ }^{9}$, dentro de los cuales encontramos las convenciones de consumo.

Ahora bien, y en lo que dice relación con la naturaleza de la institución en estudio, dos son las posturas tradicionales que imperan en nuestra tradición jurídica, a saber: aquella que lo entiende como un supuesto de responsabilidad extracontractual y aquella otra que lo concibe como un principio general del derecho.

En efecto, una primera tesis - mayoritaria y compartida por un amplio grupo de juristas chilenos y extranjeros ${ }^{10}$ - trata el abuso del derecho a propósito de la responsabilidad

${ }^{7}$ Rotondi, Mario, “L'abuso di Diritto. Aemulatio”, CEDAM, Padova, 1979, p. 17, citado por Terrazas Ponce, Juan David, op. cit., p. 280.

${ }^{8}$ www.rae.es, revisado el 01.05.2011.

${ }^{9}$ Cfr. Loewenwarter, Víctor, "Consultorio Jurídico. A través de la jurisprudencia moderna de la Corte Suprema y de los Tribunales Superiores sobre cuestiones de Derecho Civil y Comercial”, Ediciones de la Universidad de Chile, 1937, p. 31. Jurisprudencia en este sentido: "Inmobiliaria Nacional Ltda. con Centrobanco", C. Ap. Santiago, Ing. 1330-1990, 09.11.1992.

${ }^{10}$ En este sentido: Alessandri Rodríguez, Arturo, "De la responsabilidad extracontractual en el Derecho Civil Chileno”, Imprenta Universitaria, Santiago, 1943, pp. 251 y siguientes; Barros, Enrique, "Tratado de responsabilidad extracontractual", Editorial Jurídica de Chile, Santiago, 2007, p. 648; Santos Ballesteros, Jorge, "El abuso del Derecho”, Editorial Universidad Javeriana, Bogotá, Colombia, 1973, p. 52. Jurisprudencia en este sentido: "De Barbieri Salinas con Autofrance Limitada”, C. Ap. Concepción, Ing. 982-2007, 22.01.2008; "Stjepovich González con Universidad de Antofagasta”, Rol 36.492-2001, 3 J.L. 
extracontractual, esto es, como un ilícito civil, de tal manera que su efecto consistiría precisamente en dar origen a una obligación de indemnización de perjuicios ${ }^{11}$. Por tal razón es que el profesor Abeliuk señala que la tesis del abuso del derecho constituye una de las consecuencias más claras de la ampliación de la responsabilidad ${ }^{12}$. De acuerdo a lo anterior, es que -para estos autores- una eventual consagración legislativa del abuso del derecho debería ubicarse a propósito de la responsabilidad extracontractual del Código Civil.

En contra de la doctrina señalada, se encuentra aquella otra tesis -minoritaria por cierto-, conforme a la cual, el abuso del derecho, constituye en realidad un principio general del derecho, pudiendo manifestarse tanto en sede contractual como extracontractual, así como en derecho público como privado ${ }^{13}$. Agrega el profesor Fueyo que este instituto no se agota en los meros derechos subjetivos y que de consagrarse en nuestro Código Civil, debería ubicarse en un título preliminar, de tal manera que resulte aplicable a todas las relaciones jurídicas ${ }^{14}$.

Adicionalmente sostiene esta última doctrina que la noción de abuso del derecho constituye en realidad una tautología, que conlleva implícita una contradicción jurídica. En efecto, estos autores parten de la premisa de que no es posible abusar de un derecho

Antofagasta, 24.05.2002, confirmada por la C. Ap. de Antofagasta, 11.12.2002, se acoge recurso de casación, C.S., Ing. 228-2003, 09.11.2004; "Stjepovich González con Universidad de Antofagasta”, C. Ap. de Antofagasta, 11.12.2002, que confirma Rol 36.492-2001, 3 J.L. Antofagasta, 24.05.2002, se acoge recurso de casación, C.S., Ing. 228-2003, 09.11.2004; “Aguila Opazo y otra con Almacenes Brautigam S.A.”, C.S., 28.05.1998, ID Microjuris: MJJ767; "Sociedad Nacional de Procesamiento de Datos S.A. con Sone Cisternas y otro", C. Ap. Santiago, Ing. 3377-2008, MJJ24766, 02.09.2010;

${ }^{11}$ En este sentido: Terrazas Ponce, Juan David, op. cit., p. 281; Art. 830 C. Co. Colombia: "El que abuse de sus derechos estará obligado a indemnizar los perjuicios que cause". Como es lógico, en caso de alegarse un supuesto de ejercicio abusivo del derecho haciéndose alusión a esta tesis, se deberán acreditar además los otros requisitos de la responsabilidad extracontractual.

${ }^{12}$ Cfr. Abeliuk Manasevich, René, "Las obligaciones", T. 1, 5ª Edición, Editorial Jurídica de Chile, Santiago, 2008, p. 212.

13 En este sentido: Alcalde Rodríguez, Enrique, "Corte de Apelaciones de Santiago y Teoría de la imprevisión. Un hito fundamental en la evolución de nuestra justicia ordinaria”, en Revista Chilena de Derecho, Vol. 34 N² 2, Santiago, 2007, p. 370; Rodríguez Grez, Pablo, "El Abuso del Derecho y el Abuso Circunstancial”, Editorial Jurídica de Chile, Santiago, 2004, pp. 377 y siguientes; Fueyo Laneri, Fernando, "El ejercicio abusivo del derecho”, p. 48; Fernández Sessarego, Carlos, op. cit., p. 4; Chapman, Charles, "El abuso del derecho de asociación en la creación de sindicatos”, en Revista de Derecho, Universidad del Norte, $\mathrm{N}^{\circ}$ 22, Colombia, 2004, p. 179.

${ }^{14}$ Fueyo Laneri, Fernando, "Instituciones de Derecho Civil Moderno", Editorial Jurídica de Chile, Santiago, 1990, pp. 275 y siguientes, citado por Terrazas Ponce, Juan David, op. cit., p. 281. Fueyo Laneri, Fernando, "El ejercicio abusivo del derecho", p. 27. En el mismo sentido: Fernández Sessarego, Carlos, op. cit., p. 4. Cabe señalar asimismo que Fueyo propone la incorporación de un artículo del siguiente tenor: "Los derechos subjetivos, públicos y privados, no podrán ejercitarse abusivamente sino conforme a las exigencias de la buena fe, el orden público y las buenas costumbres imperantes. / Todo acto u omisión que por la intención de su autor, o por su culpa o negligencia, por su objeto o por las circunstancias en que se realice sobrepase manifiestamente los límites del ejercicio de un derecho según queda establecido en el inciso primero, con daño para tercero, dará lugar a la correspondiente indemnización y, según las circunstancias del caso, a la adopción de prontas medidas judiciales o administrativas que impidan la persistencia en el abuso o contrarrestar las amenazas evidenciadas. Siendo posible, se dispondría preferentemente la reposición al estado de hecho anterior. / La presente disposición no se aplica a los derechos que por su naturaleza o en virtud de la ley pueden ejercerse discrecionalmente", en Fueyo Laneri, Fernando, "El ejercicio abusivo del derecho", p. 51. 
(Neminem laedit qui suo jure utitud), de tal manera que lo que la tesis mayoritaria entiende por tal constituye el ejercicio de prerrogativas de las que verdaderamente se carece. Es más, de acuerdo a esta tesis, al ejercerlas se actuaría infringiendo el ordenamiento jurídico, en razón de un mero espejismo o sombra de facultad que en realidad no existe. Así las cosas, un acto podría ser conforme o contrario al derecho subjetivo de que se trate -un derecho se tiene o no se tiene-, mas no sería posible que presente los dos estados de manera simultánea ${ }^{15}$.

La importancia de optar por una tesis u otra radica en los disímiles efectos jurídicos que de ellas se derivan. En efecto, si se opta por la tesis del ilícito civil, la sanción será la indemnización de perjuicios, en tanto que si se prefiere la doctrina del principio general del derecho, el abanico de posibles consecuencias jurídicas se amplía considerablemente. Lo anterior, por cuanto, de acuerdo a esta última línea de pensamiento, la obligación de resarcimiento constituiría sólo uno de los posibles efectos jurídicos del abuso del derecho, al cual se sumarían otros, tales como la paralización del acto lesivo, la declaración de nulidad de un acto, el rechazo de una acción judicial, etc. ${ }^{16}$. Alessandri, por su parte -y de forma más conclusiva-, estima que si bien el efecto normal es la acción de resarcimiento el abuso del derecho puede dar origen al nacimiento de otras obligaciones y exigencias, tales como la adopción de medidas que atenúen el daño, la autorización para contraer matrimonio (Arts. 112, 143 y 258 C.C.), el cegamiento de un pozo (Art. 945 C.C.), la ineficacia del acto abusivo, etc ${ }^{17}$.

En cualquier caso, ambas corrientes coinciden en un punto: en nuestro sistema jurídico los derechos no son absolutos -salvo los denominados discrecionales, tal como se verá-, sino que, por el contrario, presentan una naturaleza relativa, encontrándose limitado su ejercicio por aquellas restricciones que el ordenamiento jurídico haya establecido a su respecto.

Ahora bien, en cuanto a los criterios y presupuestos que se deben utilizar para determinar cuándo existe ejercicio abusivo de un derecho, no existe consenso, habiendo planteado la doctrina disímiles respuestas.

Según Rodríguez y Alcalde ${ }^{18}$, se debe atender al interés que se pretende alcanzar con el ejercicio de la prerrogativa, entendiendo por tal a la "representación de un provecho que es legítimo satisfacer" ${ }^{19}$. De esta manera, si el interés que se procura alcanzar se encuentra dentro de los límites delineados en la norma no existirá abuso del derecho. Por el contrario, si aquél no se encuentra jurídicamente protegido, se configurará un supuesto de abusividad. Por tal razón es que Fueyo y Domínguez sostienen que en estos casos se produciría una desviación

${ }^{15}$ En este sentido: Rodríguez Grez, Pablo, op. cit., p. 138; Fueyo Laneri, Fernando, "El ejercicio abusivo del derecho", p. 48; Alcalde Rodríguez, Enrique, op. cit., p. 370. Gatti, Edmundo, "Comentarios al Proyecto de Código Civil”, en Revista Verbae Iustitia, Vol. 7, No 12, p. 108; Terrazas Ponce, Juan David, op. cit., p. 282.

${ }^{16}$ Cfr. Terrazas Ponce, Juan David, op. cit., p. 282.

${ }^{17}$ Alessandri Rodríguez, Arturo, op. cit., p. 288.

${ }^{18}$ Cfr. Rodríguez Grez, Pablo, op. cit., pp. 87, 137 y 177; Alcalde Rodríguez, Enrique, op. cit., p. 370.

${ }^{19}$ Rodríguez Grez, Pablo, op. cit., p. 177. Cabe señalar que una tesis en tal sentido podría encontrar fundamento además en la concepción del derecho subjetivo como protección del interés. Al respecto se puede consultar Enneccerus, Ludwig, "Derecho Civil. Parte General”, Vol. 1, Bosch Publicaciones Jurídicas, Buenos Aires, 1948, p. 287. 
del ordenamiento jurídico -propósito torcido-, toda vez que el sujeto que abusa pretende obtener un provecho contrario al permitido, a sabiendas de que ello es así, tal como ocurre en las hipótesis de simulación y fraude a la ley ${ }^{20}$.

Este criterio ha sido seguido por alguna jurisprudencia nacional de la siguiente manera: "no tiene relevancia ejercer el derecho de buena o de mala fe pues la legitimidad del ejercicio no se sustenta en la intención sino en el interés que se procura satisfacer. Por lo mismo, cabe concluir que no se abusa del derecho propiamente tal sino que se abusa del interés tutelado por el derecho positivo, sea desviándolo o excediéndolo" 21 .

Ahora bien, en cuanto al momento al cual se debe atender para establecer el interés protegido, Santos estima que se debe considerar a aquel imperante en el momento en el cual se suscita el conflicto y no a aquel que consideró el legislador al dictar la norma ${ }^{22}$.

Santos Ballesteros, por su parte, y utilizando un criterio funcional, opina que se abusa de un derecho cuando se ejerce en contra del destino natural por el cual lo estableció el legislador, así como cuando se atenta en contra del fin económico o social del derecho ${ }^{23}$. Entre nosotros, una consideración como la señalada podría encontrar asidero en la función social de la propiedad -naturalmente si se entiende que existe dominio sobre los derechosconsagrada en el Art. $19 \mathrm{~N}^{\circ} 24 \mathrm{CPR}$. Nuestra jurisprudencia ha reconocido lo anterior, de la siguiente manera: "Los derechos son facultades que la ley otorga al individuo, pero no para que los utilice a su antojo, sino para realizar determinados fines. Los derechos, a más de su aspecto individual, tienen una finalidad social que llenar, de la que su titular no puede prescindir. Deben pues, ejercerse de acuerdo con los fines para los que han sido otorgados" 24 .

Para el profesor Terrazas, en tanto, deben presentarse de manera copulativa un ánimo manifiesto de perjudicar (animus nocendi) y la falta de interés o necesidad en el derecho que se ejerce ${ }^{25}$.

${ }^{20}$ Cfr. Fueyo Laneri, Fernando, "El Fraude a la ley”, RDJ. LXXXVIII.Nº 2.1991, MJD41; Domínguez Águila, Ramón, "Fraus Omnia Corrumpit: Notas Sobre el Fraude en el Derecho Civil”, RDJ. LXXXIX. $\mathrm{N}^{\circ} 3.1992, \mathrm{MJD} 57$.

21 “Sociedad Nacional de Procesamiento de Datos S.A. con Sone Cisternas y otro", C. Ap. Santiago, Ing. 3377-2008, MJJ24766, 02.09.2010.

22 Santos Ballesteros, Jorge, op. cit., p. 21.

${ }^{23}$ Doctrina en este sentido: Santos Ballesteros, Jorge, op. cit., pp. 13 y 15; Jurisprudencia en este sentido: Gaceta Judicial, Corte Suprema de Justicia, Casación 21.02.1938, T. XLVI, p. 60, citado por Chapman, Charles, op. cit., p. 180; Derecho Comparado en este sentido: Art. 372 C.C. Paraguay: "Los derechos deben ser ejercidos de buena fe. El ejercicio abusivo de los derechos no está amparado por la ley y compromete la responsabilidad del agente por el perjuicio que cause, sea cuando lo ejerza con intención de dañar aunque sea sin ventaja propia, o cuando contradiga los fines que la ley tuvo en mira al reconocerlos. La presente disposición no se aplica a los derechos que por su naturaleza o en virtud de la ley pueden ejercerse discrecionalmente"; Art. 334 C. C. Portugal: "É ilegítimo o exercício de um direito, quando o titular exceda manifestamente os limites impostos pela boa fé, pelos bons costumes ou pelo fim social ou económico desse direito"; en español: "Es ilegítimo el ejercicio de un derecho, cuando el titular excede manifiestamente los límites impuestos por la buena fe, las buenas costumbres o el fin social o económico de ese derecho".

24 "Stjepovich González con Universidad de Antofagasta”, Rol 36.492-2001, 3 J.L. Antofagasta, 24.05.2002, confirmada por la C. Ap. de Antofagasta, 11.12.2002, se acoge recurso de casación, C.S., Ing. 228-2003, 09.11.2004.

${ }^{25}$ Cfr. Terrazas Ponce, Juan David, op. cit., p. 282. En el mismo sentido: Santos Ballesteros, Jorge, op. cit., p. 39. Alessandri Rodríguez, Arturo, op. cit., p. 260. Derecho Comparado en este sentido: Art. 372 C. 
También se han señalado otros criterios o presupuestos, tales como la producción de un daño para la víctima ${ }^{26}$, el establecimiento de gravámenes innecesarios ${ }^{27}$, la afectación del ejercicio legítimo del derecho de un tercero ${ }^{28}$, la falta de un interés serio y real ${ }^{29}$, la posición subjetiva del sujeto que abusa (ánimo de causar daño) ${ }^{30}$ y la actuación de mala $\mathrm{fe}^{31}$.

Cabe señalar por último -tal como se adelantó- que según Fueyo quedarían exentos de la teoría en comento los derechos calificados como discrecionales, los cuales -además de ser absolutos y excepcionales- no admiten ejercicio abusivo alguno, entre las que cita las siguientes prerrogativas: testar dentro de los límites de las asignaciones forzosas, revocar un testamento en todo o en parte, desheredar por las causas legales a ciertas y determinadas personas, alegar la nulidad y la prescripción, el ejercicio de la actio communis dividundo -salvo que medie pacto de indivisión-, etc. ${ }^{32}$.

C. Paraguay: "Los derechos deben ser ejercidos de buena fe. El ejercicio abusivo de los derechos no está amparado por la ley y compromete la responsabilidad del agente por el perjuicio que cause, sea cuando lo ejerza con intención de dañar aunque sea sin ventaja propia, o cuando contradiga los fines que la ley tuvo en mira al reconocerlos"; Art. 1912 C.C. México: "Cuando al ejercitar un derecho se cause daño a otro, hay obligación de indemnizarlo si se demuestra que el derecho solo se ejercitó a fin de causar el daño, sin utilidad para el titular del derecho"; Art. 840 C.C. México: "No es lícito ejercitar el derecho de propiedad de manera que su ejercicio no dé otro resultado que causar perjuicios a un tercero, sin utilidad para el propietario".

${ }^{26}$ Fueyo Laneri, Fernando, "El Fraude a la ley". Jurisprudencia en el mismo sentido: "Stjepovich González con Universidad de Antofagasta”, C.S., Ing. 228-2003, 09.11.2004, que acoge recurso de casación en el fondo respecto de C. Ap. de Antofagasta, 11.12.2002, que confirma Rol 36.492-2001, 3 J.L. Antofagasta, 24.05.2002. Derecho Comparado en este sentido: Art. 226 BGB: "Schikaneverbot. Die Ausübung eines Rechts ist unzulässig, wenn sie nur den Zweck haben kann, einem anderen Schaden zuzufügen"; en español: "El ejercicio de un derecho no está permitido, si sólo tiene por objeto generar un daño a otro".

27 "Púa Córdova con Director Nacional (S) de Vialidad”, Recurso de Protección, C.S. Ing. 2832-1999, ID Microjuris: MJJ486, 07.09.1999.

28 "Romagosa Irart con Club Árabe de Tiro al Vuelo", C. Ap. San Miguel, Ing. ID Microjuris: MJJ5323, 23.01.1985.

${ }^{29}$ Santos Ballesteros, Jorge, op. cit., pp. 20 y 62.; Jurisprudencia en este sentido: Sentencia Tribunal de Colmar, 1855, Francia, citado por Fueyo Laneri, Fernando, "El ejercicio abusivo del derecho", p. 24.

30 Santos Ballesteros, Jorge, op. cit., p. 20. Sentencias del Tribunal Supremo español, 28.11.1967 y 5.06.1972, citados por Fueyo Laneri, Fernando, "El ejercicio abusivo del derecho”, p. 38. Según Santos Ballesteros, el animus nocendi en realidad "no es más que una aplicación de la culpa delictual que se caracteriza por la intención perversa, por la intención de perjudicar”, en Santos Ballesteros, Jorge, op. cit., p. 53.

${ }^{31}$ Diez Picazo, Luis, "El abuso del derecho y el fraude de la ley en el nuevo Título Preliminar del Código Civil y el problema de sus recíprocas relaciones", en "Documentación Jurídica”, Secretaría General Técnica del Ministerio de Justicia, No 4, Madrid, octubre-diciembre 1974, pp. 1329 y ss., citado por Fueyo Laneri, Fernando, "El ejercicio abusivo del derecho", p. 25.

32 Cfr. Fueyo Laneri, Fernando, "El ejercicio abusivo del derecho", pp. 27 y 49. En el mismo sentido: Villegas Villegas, Germán, "El Abuso del Derecho”, Facultad de Ciencias Económicas y Jurídicas, Pontificia Universidad Javeriana, Bogotá, 1967, pp. 45 y 46. Derecho Comparado en este sentido: Art. 372 C. C. Paraguay: "La presente disposición no se aplica a los derechos que por su naturaleza o en virtud de la ley pueden ejercerse discrecionalmente". En un sentido diverso, Rodríguez Grez señala: "No puede afirmarse (...) que el derecho es absoluto o es relativo. Esta nomenclatura es equívoca e inductiva a error. Lo que sucede es algo diametralmente distinto. La ley ha previsto, en ciertos casos, que sea la voluntad del titular la que deslinde el interés que pretende satisfacer", en Rodríguez Grez, Pablo, op. cit., p. 160. 


\section{LOS DERECHOS DE LOS CONSUMIDORES COMO DERECHOS SUBJETIVOS}

Cabe ahora preguntarse si las garantías consagradas en la Ley $\mathrm{N}^{\circ} 19.496$ constituyen verdaderos derechos subjetivos, lo que reviste especial relevancia, por cuanto únicamente puede presentarse un supuesto de ejercicio abusivo o irregular, si nos encontramos en presencia de una prerrogativa de tal naturaleza ${ }^{33}$.

Qué debemos entender entonces por derecho subjetivo. Al respecto, se debe considerar primeramente que la ciencia jurídica romana no se estructuró sobre la base de facultades, sino que se presentaba "como un sistema de acciones" 34 . De esta manera, la voz ius -que en nuestros días se identifica con el derecho subjetivo- en realidad se refería a una 'posición justa', que comprendía todas aquellas consecuencias jurídicas que se derivan de una determinada situación, las cuales podían encontrarse constituidas tanto por facultades como deberes ${ }^{35}$.

Con el correr de los años -y particularmente a partir de la Baja Edad Media-, se comienza a independizar la prerrogativa de cualquier carga o deber que se le encontrare asociado, pasando el derecho subjetivo a identificarse con el término de facultad ${ }^{36}$, dando origen a una concepción que se encuentra vigente hasta nuestros días.

Lo anterior se entiende sin perjuicio de que autores como Borda continúan sosteniendo que todo derecho subjetivo presentaría la estructura de un poder deber, aun cuando en la mayoría de las ocasiones prevalezca la facultad por sobre el débito ${ }^{37}$.

Ahora bien, y en lo que dice relación con la materia que nos ocupa, cabe señalar que el Art. 3 LPC $^{38}$ establece el siguiente catálogo de derechos calificados como básicos por el legislador: a la libre elección del bien o servicio -manifestación del principio de la libertad contractual-, a una información veraz y oportuna, a no ser discriminado

33 Terrazas Ponce, Juan David, op. cit., p. 283: "Sólo en la medida que entendamos el "derecho" como "facultad", podemos concebir que se ha excedido en el ejercicio de "las mismas y estaremos en la hipótesis que regularmente suele concebirse como propia del abuso del derecho".

34 Terrazas Ponce, Juan David, op. cit., p. 286.

${ }^{35}$ Cfr. Terrazas Ponce, Juan David, op. cit., p. 285.

36 Cfr. Guzmán Brito, Alejandro, "Para la historia del derecho subjetivo", en Revista Chilena de Derecho, Pontificia Universidad Católica de Chile, Vol. 2, Santiago, 1975, pp. 57 y 58. Guzmán Brito, Alejandro, "Historia de la denominación del derecho-facultad como "subjetivo"”, en Revista de Estudios Histórico-Jurídicos, Vol XXV, Valparaíso, 2003, p. 407.

${ }^{37}$ Cfr. Borda A., Guillermo, Prólogo, en Fernández Sessarego, Carlos, “Abuso del derecho”, Editorial Astrea, Buenos Aires, 1992, p. VIII.

${ }^{38}$ Art. $3^{\circ}$ LPC: "Son derechos y deberes básicos del consumidor: a) La libre elección del bien o servicio. El silencio no constituye aceptación en los actos de consumo. b) El derecho a una información veraz y oportuna sobre los bienes $y$ servicios ofrecidos, su precio, condiciones de contratación y otras características relevantes de los mismos, y el deber de informarse responsablemente de ellos; c) El no ser discriminado arbitrariamente por parte de proveedores de bienes $y$ servicios; d) La seguridad en el consumo de bienes o servicios, la protección de la salud y el medio ambiente y el deber de evitar los riesgos que puedan afectarles; e) El derecho a la reparación e indemnización adecuada y oportuna de todos los daños materiales y morales en caso de incumplimiento de cualquiera de las obligaciones contraídas por el proveedor, y el deber de accionar de acuerdo a los medios que la ley le franquea, y f) La educación para un consumo responsable, y el deber de celebrar operaciones de consumo con el comercio establecido". 
arbitrariamente, a la seguridad en el consumo de bienes o servicios, a la reparación e indemnización de los daños sufridos y a la educación para el consumo responsable.

Pues bien, sucede que junto a las garantías indicadas el legislador incluyó además una nómina de deberes, cuyo sujeto pasivo es igualmente el consumidor, y que contempla las siguientes cargas: el deber de informarse responsablemente; el deber de evitar riesgos, el deber de accionar de acuerdo a los medios que la ley franquea y el deber de contratar con el comercio establecido. De la lectura de la norma transcrita surge por tanto la necesaria pregunta acerca de si se trata de verdaderas obligaciones jurídicas -cuyo incumplimiento genere sanciones- o si por el contrario no tienen fuerza obligatoria, lo cual presentará importancia a la hora de determinar la naturaleza de los derechos de los consumidores.

Al respecto, el profesor Fernández Fredes da una respuesta negativa, sosteniendo que los deberes consagrados en el Art. 3 no constituyen obligaciones propiamente tales, obedeciendo su consagración únicamente "a un propósito didáctico y programático, vinculado al fomento de una actitud diligente y responsable de parte de los consumidores" 39.

Guerrero Becar tiene una opinión similar, fundamentada en la ausencia de acciones en contra del consumidor infractor. Al respecto, explica: "Atendido que la LPDC no contempla sanciones a la inobservancia de los deberes que ella misma enuncia en su artículo 3, no se los puede caracterizar como deberes jurídicos; y más bien parecen tener la connotación de conductas esperadas de parte del consumidor. Sin acción ni forma de exigibilidad en el marco del Derecho de consumo, los deberes impuestos por la LDPC a los consumidores, más que una imposición o carga al consumidor, parecen estar redactados en forma de declaración de principios o conductas esperadas, que el legislador aspira como actitud de un consumidor frente a un incumplimiento de su proveedor; pero, al parecer, no previó el supuesto de un incumplimiento propiamente imputable al consumidor, lo que constituiría una importante omisión" 40.

En un sentido diverso, y de acuerdo a otra línea de pensamiento -que considero correcta-, los denominados "deberes de los consumidores" constituyen verdaderas prescripciones vinculantes para los usuarios, y cuya transgresión generará las consecuencias jurídicas que dependan de cada caso.

Ahora bien, si se analiza el problema planteado desde el punto de vista de los efectos jurídicos, podría sostenerse que en realidad se trataría de lo que Candian denomina como "cargas", cuyo incumplimiento aparejaría la disminución de una parcela de protección. Al respecto, explica este autor: "A una norma jurídica que instituye la necesidad de actuación no siempre sigue una 'obligación', en el sentido técnico (...), esto es: de deber complementario a un derecho de otro. Hay actuaciones a las cuales el sujeto está obligado no a favor de otros, porque tengan un derecho complementario a las dichas actuaciones, sino porque el no actuar importa un

${ }^{39}$ Fernández Fredes, Francisco, “Nueva Ley del Consumidor: innovaciones y limitaciones”, en Revista Perspectivas en Política, Economía y Gestión, Facultad de Ingeniería y Ciencias, Universidad de Chile, Vol. $1 \mathrm{~N}^{\circ}$ 2, 1998, Santiago, p. 115.

${ }^{40}$ Guerrero Becar, José Luis, "La acción temeraria en la Ley No 19.496 sobre Protección de los Derechos del Consumidor”, en Revista de Derecho, Pontificia Universidad Católica de Valparaíso, Valparaíso, 2008, p. 193. 
daño para el primero: la imposibilidad de ejercitar ciertas facultades jurídicas, o la pérdida de ciertas situaciones preconstituidas a favor suyo" ${ }^{41}$.

Ahora bien, y de acuerdo a este planteamiento, ¿se trata de obligaciones correlativas de los derechos que enuncia o, por el contrario, se trataría de cargas independientes?

Una primera lectura de la norma podría considerar que, si bien se trata de prescripciones vinculantes, constituyen instituciones independientes. En este caso, si bien pueden generarse efectos jurídicos para el consumidor, no alteran la noción de derecho entendido como facultad.

Conforme a una segunda línea de pensamiento, tanto los deberes como las facultades de los consumidores son correlativos, de tal manera que si no se cumplen los primeros -cuando ello corresponda- no sería posible exigir el cumplimiento de los segundos. Desde este punto de vista, las potestades reconocidas en los mismos literales -esto es, el derecho a la información, a la protección de la salud y medio ambiente, a la reparación e indemnización, y a la educación para el consumo responsable- se explicarían mejor conforme a la teoría romana de la posición justa-actualizada modernamente por Borda- que por la tesis tradicional de los derechos subjetivos como meras facultades, toda vez que ella sería omnicomprensiva, tanto de las prerrogativas como de las cargas que la posición de consumidor conlleva.

Ahora bien, qué ocurre con el resto de los derechos consagrados en la Ley No 19.496, mas no enunciados en su Art. 3. En estos casos, si se invoca una garantía, que se encuentre relacionada con alguno de los derechos básicos establecidos en dicha disposición, se generará el mismo efecto que el señalado.

\section{LAS Limitaciones AL EJERCICIO DE LOS DERECHOS DE LOS CONSUMIDORES}

Las líneas de pensamiento vigentes en las épocas de dictación de las leyes de protección de los derechos de los consumidores distan mucho de aquellas otras imperantes en el período de codificación. En efecto, no sólo se ha abandonado el individualismo y el pensamiento liberal -que incluyó la voz "a su arbitrio" en la definición del dominio-, sino que además se ha otorgado un nuevo contenido a las facultades derivadas de los derechos subjetivos. De esta manera, en aras de la moral, la justicia y la buena $\mathrm{fe}^{42}$, se fueron abandonando progresivamente las teorías que defendían el ejercicio absoluto de los derechos, fundamentadas en la noción liberal de la propiedad ${ }^{43}$.

41 Candian, Aurelio, "Instituciones de Derecho Privado", Unión Tipográfica Hispano Americana, México, 1961, p. 29.

42 Borda A., Guillermo, op. cit., p. VII.

43 Según Lira, nuestro Código Civil, siguiendo a su símil francés -que fue calificado como "el código de los propietarios"- concibió a la propiedad como absoluta, y libre de las trabas a las que se encontraba sujeta en la legislación colonial, en Lira Urquieta, Pedro, "El Código Civil Chileno y su época”, Editorial Jurídica de Chile, Santiago, 1956, pp. 19 y 68. Según Cuneo, a partir de los años 20 la propiedad plena, comienza a presentar una serie de importantes restricciones, fundadas en la Constitución y en los preceptos legales, que progresivamente le han ido reconociendo una función social, en Cuneo Macchiavello, Andrés, 
En efecto, hoy por hoy, y tal como lo ha señalado Borda, "sea que se bable de derechos subjetivos o de situaciones jurídicas subjetivas, lo indudable es que los derechos de la persona humana no son absolutos, sino que están limitados por los derechos y los justos intereses de los demás miembros de la comunidad" 44 .

Villegas se ha pronunciado en el mismo sentido, señalando que el interés individual se debe subordinar al de la sociedad toda, por tener esta última una mayor jerarquía, de tal manera que todo derecho subjetivo conllevaría un componente comunitario ${ }^{45}$. No obstante, reconoce que la perspectiva social que se le atribuye a los derechos subjetivos implica una funcionalidad primaria y otra secundaria: "Servir primeramente al titular, sobre todo en el campo del derecho privado, y luego satisfacer un interés colectivo ajustándose a la finalidad social" ${ }^{46}$, de tal manera que no se podría sacrificar la individualidad y todo lo que ello conlleva, en aras de la colectividad. En efecto, para este autor "(bien) distinto es decir: que los derechos 'tienen' función social a afirmar que 'son' función social" 47.

En cualquier caso, la limitación de los derechos a la que se alude se encuentra íntimamente relacionada con la teoría del abuso del derecho, por cuanto éste se ejerce de manera abusiva cuando se transgreden los límites establecidos para ello, concurriendo los demás presupuestos que esta institución exige. En este sentido ha señalado Fernández Sessarego: "Aceptar la teoría del abuso del derecho es mostrar la intrínseca falsedad de la máxima qui suo iure utitur neminem laedit que, por siglos, justificó excesos y abusos en el ejercicio de los derechos subjetivos" 48 .

Corresponde entonces ahora proponer los límites a los cuales se encuentran sujetos los consumidores en el ejercicio de sus prerrogativas. En cualquier caso, se debe considerar que conforme al Art. $19 \mathrm{~N}^{\circ} 26 \mathrm{CPR}$, las limitaciones legales a los derechos no pueden afectarlos en su esencia, ni imponer condiciones, tributos o requisitos que impidan su libre ejercicio.

Partiendo como base de la definición establecida en el Código Civil -y asumiendo el derecho de propiedad sobre las cosas incorporales- resulta claro que el dominio sobre los derechos de los consumidores otorga a estos últimos la potestad para beneficiarse o

“Copropiedad inmobiliaria y propiedad común”, en Guzmán Brito, Alejandro, Editor, "El Código Civil de Chile (1855-2005), Editorial LegalPublishing, Santiago, 2009, p. 410.

${ }^{44}$ Borda A., Guillermo, op. cit., p. IX. En el mismo sentido: Diez Picazo, Luis, op. cit., pp. 1329 y ss., citado por Fueyo Laneri, Fernando, "El ejercicio abusivo del derecho”, p. 25.

45 Villegas Villegas, Germán, op. cit., p. 29.

46 Villegas Villegas, Germán, op. cit., p. 30.

47 Villegas Villegas, Germán, op. cit., p. 31.

${ }^{48}$ Fernández Sessarego, Carlos, op. cit., p. 9. En el mismo sentido: Santos Ballesteros, Jorge, op. cit., p. 66: "Instituciones como el Abuso del Derecho tienden a restringir el carácter absoluto que presenta esta materia según las orientaciones de la teoría clásica". La misma idea se puede desprender del Derecho Comparado: Art. 7 C.C. España: "1. Los derechos deberán ejercitarse conforme a las exigencias de la buena fe. 2. La Ley no ampara el abuso del derecho o el ejercicio antisocial del mismo. Todo acto u omisión que por la intención de su autor, por su objeto o por las circunstancias en que se realice sobrepase manifiestamente los límites normales del ejercicio de un derecho, con daño para tercero, dará lugar a la correspondiente indemnización y a la adopción de las medidas judiciales o administrativas que impidan la persistencia en el abuso"; Art. 1185 inc. $2^{\circ}$ C.C. Venezuela: "Debe igualmente reparación quien haya causado un daño a otro, excediendo, en el ejercicio de su derecho, los limites fijados por la buena fe o por el objeto en vista del cual le ha sido conferido ese derecho". 
perjudicarse de ellos, así como a perjudicar o beneficiar a otros ${ }^{49}$, siempre que se actúe dentro de la esfera de la garantía de la que se es titular. De acuerdo a lo anterior es que existirían dos grandes categorías de limitaciones, a saber: aquellas de naturaleza normativa y aquellas otras que se derivan de los derechos ajenos ${ }^{50}$.

\section{Limitaciones normativas de los derechos de los consumidores}

\section{a) La protección del consumidor medio}

Desde un tiempo a esta parte, los sistemas jurídicos han acudido a la utilización de patrones abstractos para asignar derechos o cargar responsabilidades, tales como el hombre razonable, el buen padre de familia, el negociante diligente, etc. ${ }^{51}$. En la materia que nos ocupa se suele recurrir a la noción de consumidor medio, entendido como aquel que "está normalmente informado y es razonablemente perspicaz, teniendo en cuenta los factores sociales, culturales y lingüísticos" 52 .

De esta manera, a quien en realidad se protege es a aquel usuario que ejerce sus derechos con una diligencia ordinaria, quedando privado de las garantías de la Ley $\mathrm{N}^{\circ} 19.496$ aquel otro que actuare de mala fe, con dolo o negligencia inexcusable ${ }^{53}$.

No obstante, la observación de la posición subjetiva del sujeto tutelado se debe realizar atendiendo al individuo medio de la categoría de consumidores a la que el producto o servicio se encuentre destinado. De esta manera no se puede utilizar, por ejemplo, el mismo criterio respecto de un adulto que de un menor de edad (usuarios de productos específicos v. gr. juguetes, coches, etc.). Esta consideración ha llevado a la doctrina a entender que la operación antedicha no puede ser realizada bajo supuestos dogmáticos, sino que, por el contrario, debe incorporar las circunstancias que rodean cada caso concreto ${ }^{54}$.

\footnotetext{
${ }^{49}$ Demsetz, Harold, "Hacia una teoría de los Derechos de Propiedad”, traducido de American Economic Review, mayo 1967, p. 1.

${ }^{50}$ Art. 582 inc. $1^{\circ}$ C.C. chileno: "El dominio (que se llama también propiedad) es el derecho real en una cosa corporal, para gozar y disponer de ella arbitrariamente; no siendo contra la ley o contra derecho ajeno".

${ }^{51}$ En este sentido: Fernández Cruz, Gastón, "Las transformaciones funcionales de la responsabilidad civil: La óptica sistémica” en Revista de la Facultad de Derecho, Universidad Nacional de San Agustín de Arequipa, p. 101; Tapia R., Mauricio, "El contrato de seguro y el exceso de responsabilidad civil", en Revista del Magíster y Doctorado en Derecho, $\mathrm{N}^{\circ}$ 1, 2007, Facultad de Derecho Universidad de Chile, p. 174. Jurisprudencia en este sentido: "Sociedad Nacional de Procesamiento de Datos S.A. con Sone Cisternas y otro", C. Ap. Santiago, Ing. 3377-2008, MJJ24766, 02.09.2010.

52 Considerando 18 DPCD 2005/29/CE.

${ }^{53}$ Según Santos Ballesteros, existiría una relación directa entre el abuso del derecho y la culpa, también considerada conforme a un criterio de normalidad: "Así pues, llegamos a la fórmula de Abuso del Derecho: toda desviación de la finalidad y espíritu de un derecho en que no incurriría un hombre prudente y diligente en las mismas circunstancias externas del autor del acto. Es pues una culpa especial y como tal debe tratarse", en Santos Ballesteros, Jorge, op. cit., p. 57. Respecto del análisis de la culpa y el abuso del derecho, ver Villegas Villegas, Germán, op. cit., pp. 72 y siguientes.

${ }^{54}$ Fernández Cruz, Gastón, op. cit., p. 115.
} 
Lo anterior presenta particular importancia en el caso de los denominados consumidores desfavorecidos o vulnerables - tales como los niños y los ancianos- ${ }^{55}$, concebidos por la OCDE como aquellos que "debido a características o circunstancias personales (por ejemplo, edad, capacidad física o mental, educación, ingreso, idioma o ubicación remota) pueden tener dificultades particulares en el acceso a la resolución de disputas y el resarcimiento" 56.

De la misma manera, se debe tomar en cuenta la clara asimetría informativa existente entre las partes de una relación de consumo. En efecto, y tal como lo ha señalado Fernández Fredes, "(es) evidente que el profesional de una actividad conoce mucho más que el profano respecto de las propiedades de los bienes y servicios que produce, comercializa o presta, como asimismo sobre sus costos y precios razonables, forma de usarlos con mayor provecho y eventuales riesgos que pueda presentar su utilización" 57 . Por el contrario, se entiende que el consumidor medio presenta una "racionalidad limitada" -esto es, "la imposibilidad de procesar adecuadamente y en el tiempo requerido la información disponible en el mercado" 58 -, la que debe ser igualmente considerada.

Entre nosotros - a diferencia de lo que ocurre en Derecho Comparado ${ }^{59}$ - no existe una norma expresa que establezca el principio en comento, no obstante poder derivarse tanto de la LPC como de su normativa complementaria.

Al respecto, se pueden citar en primer lugar los Arts. 20 y 3 bis letra b) LPC, conforme a los cuales se priva al consumidor de la garantía legal y del derecho a retracto en contratos electrónicos o celebrados a distancia respectivamente, en caso de que el producto se haya deteriorado por un hecho que le sea imputable, estableciendo una noción subjetiva amplia que incluye tanto a la culpa como el dolo ${ }^{60}$. En este sentido, la jurisprudencia nacional ha fallado que no procede la garantía legal en el caso de un accidente automovilístico que fue producido por la impericia del conductor y no por la defectuosidad del producto ${ }^{61}$.

55 En este sentido, se ha recomendado que se tenga en especial consideración a este tipo de consumidores tanto por parte de los proveedores (publicidad), así como en las políticas de educación, en OCDE: "Recomendación de la OCDE sobre Resolución de Disputas y Resarcimiento a los Consumidores", 12.07.07, disponible en http://www.oecd.org/dataoecd/3/36/40060255.pdf, revisado el 09.05.2011, p. 13 .

56 OCDE, op. cit., p. 8.

${ }^{57}$ Fernández Fredes, Francisco, "Manual de Derecho Chileno de Protección al Consumidor", Editorial LexisNexis, Santiago, 2003, p. 4.

58 Fuentes, Fernando y Saavedra, Eduardo, “Análisis de Tres Elementos de la Ejecución de la Política de Protección al Consumidor, con Énfasis en la Comparación con las Mejores Prácticas de otros Países”, Ministerio de Economía, 2009, disponible en http://www.economia.cl/1540/articles-189395_recurso_1. pdf, revisado el 20.09.10, p. 12. En el mismo sentido Engel, Eduardo, "Protección a los consumidores en Chile. ¿Por qué tan poco y tan tarde?”, en Revista Perspectivas en Política, Economía y Gestión, Vol. 1 N ${ }^{\circ} 2$, 1998, Universidad de Chile, p. 148: "Como la racionalidad de los individuos es limitada, éstos tienen problemas para procesar la información disponible sobre los bienes que están considerando comprar".

59 Art. 3 letra a) DS 006-2009 PCM, Perú.

${ }^{60}$ Durante la fase de la discusión de la LPC se propuso mediante una indicación que fue aprobada que se cambiara la expresión original del proyecto "descuido del" por "hecho imputable al", en atención a que la primera podría dar a entender que abarcaría únicamente la culpa o la negligencia. Senado, Segundo Trámite Constitucional, Primer Informe Comisión de Economía, 15.03.1995, cuenta en Sesión 45, Legislatura 330, Boletín 446-03.

61 “Sernac con Sociedad Comercial Automotriz S.A.”, C. Ap. Santiago, Ing. 1.093-2010, 09.07.2010, que revoca Rol 12.167-3-09, JPL Quilicura, 20.11.09. 
De la misma manera, y en lo que dice relación con la responsabilidad contractual, se debe considerar que conforme al Art. 1 LPC No 1 y 2 el contrato de consumo es una convención onerosa $^{62}$, por lo que la diligencia esperada de ambas partes es precisamente la ordinaria (Arts. 44 y 1547 C.C. $^{63}$ ), lo que no viene sino a reafirmar la tutela del consumidor medio.

En el mismo sentido, pero esta vez en relación a la responsabilidad derivada de los productos defectuosos, se ha sostenido que ella se configura únicamente -concurriendo los demás requisitos legales- si el producto ha sido utilizado de manera razonablemente previsible por parte del consumidor, razón por la cual no se dará lugar a indemnización alguna si el consumidor utilizó el bien o servicio de manera indebida (Art. 26 Decreto 3466, Colombia), o bien si actuó con culpa (Art. 8 LRCPD España). Así las cosas, se excederá el derecho conferido -y por tanto se ejercerá abusivamente- "cuando el comportamiento de la víctima manifieste un rechazo de las precauciones más elementales que estuvieren a su alcance o cuando su comportamiento atestigüe una temeridad activa, es decir, un esfuerzo becho para desafiar las reglas de seguridad"64. Este es el régimen compartido ampliamente por el Derecho Comparado y recomendado asimismo por la ONU para sus Estados miembro ${ }^{65}$.

Entre nosotros, si bien no se encuentra consagrada una regla como la señalada en la LPC -en atención a que ella no contempla una regulación clara sobre productos defectuosos- sí es posible reconocerla en su normativa complementaria ${ }^{66}$.

${ }^{62}$ Existe consenso en entender que el contrato de consumo es un contrato oneroso. Lo anterior se exige únicamente respecto del contrato principal, por cuanto el contrato de consumo accesorio se contagia de la suerte del primero, de acuerdo a las reglas generales, tal como ocurre con la donación de un bien por la compra de otro. Lo mismo ocurre en caso de que un producto o servicio tenga por finalidad crear condiciones propicias para la celebración de un contrato (Ej: estacionamientos gratuitos). En este sentido: Fernández Fredes, Francisco, "Nueva Ley del Consumidor: innovaciones y limitaciones”, pp. 110 y 111; Fernández Fredes, Francisco, "La protección jurídica de la calidad", en Pizarro Wilson, Carlos, Editor, "Temas de Derecho del Consumidor", Cuadernos de análisis jurídico, Ediciones Universidad Diego Portales, Servicio Nacional del Consumidor, Santiago, 1997, p. 37; Jara Amigo, Rony, “Ámbito de aplicación de la Ley chilena de protección al consumidor: inclusiones y exclusiones", en Corral Talciani, Editor, "Derecho del consumo y protección al consumidor", Cuadernos de Extensión N ${ }^{\circ}$ 3, Facultad de Derecho, Universidad de los Andes, Santiago, 1999, p. 58; Momberg Uribe, Rodrigo, “Ámbito de Aplicación de la Ley Nº 19.496 sobre Protección de los Derechos de los Consumidores”, en Revista de Derecho, Universidad Austral de Chile, Vol. XVII, Valdivia, diciembre 2004 , pp. 41 a 62.

63 Art. 1547 inc. $1^{\circ}$ C.C.: "El deudor no es responsable sino de la culpa lata en los contratos que por su naturaleza sólo son útiles al acreedor; es responsable de la leve en los contratos que se hacen para beneficio recíproco de las partes; y de la levísima, en los contratos en que el deudor es el único que reporta beneficio"; Art. 44 inc. $3^{\circ}$ C.C.: "Culpa leve, descuido leve, descuido ligero, es la falta de aquella diligencia y cuidado que los hombres emplean ordinariamente en sus negocios propios. Culpa o descuido, sin otra calificación, significa culpa o descuido leve. Esta especie de culpa se opone a la diligencia o cuidado ordinario o mediano".

${ }^{64}$ Stiglitz, Gabriel y Gandolfo de Stiglitz, Ana Claudia, "Responsabilidad estricta del industrial por daños al consumidor", en "Derecho del Consumidor", N 7, Editorial Juris, Rosario, 1996, p. 26.

${ }^{65}$ Arts. 5 letra a, 8 y 32 DS 006-2009 PCM, Perú; Art. 5 LDC Argentina; Art. 35.1 LPCDC Panamá; Art. 82 LFPC México; Art. 2 letra a DSGP; Arts. 11 y 12.1 LGDCU, España; DPCDECMI/ 2005/29/CE, considerando 18; Directrices de las Naciones Unidas para la protección del consumidor, ampliadas en 1999, III.11, disponible en http://www.un.org/esa/sustdev/publications/consumption_sp.pdf, revisado el 09.05.2011.

${ }^{66}$ Decreto 114/2005/MinSal, Reglamento sobre seguridad de los juguetes: Art. 4: "Los juguetes deberán ser seguros para los usuarios en circunstancias de uso normal o razonablemente previsible de los mismos"; Art. 15: "Los 
En el mismo sentido, nuestra jurisprudencia ha reconocido el uso razonable por parte del consumidor, negando indemnización de perjuicios a aquel usuario que utilizó un aparato electrónico - usualmente llamado cautín- de manera inadecuada, no tomando las providencias normales mínimas esperables, tales como desconectar la corriente eléctrica al iniciar la reparación ${ }^{67}$.

En otra ocasión, mediante una consideración similar, el tribunal absolvió al proveedor de la condena infraccional y civil, argumentando que el consumidor si bien había sufrido un daño producto de la caída de una escalera mecánica, ello se habría generado por su propia negligencia: "la conducta desplegada por el denunciante en el motivo que antecede resulta imprudente puesto que se trata de una persona que afirmó tener 54 años de edad y poseer estudios técnicos en computación, en otras palabras, se trata de persona adulta y educada que bien pudo prever los resultados de su acción antes de proceder en la forma como relata, cuestión que esta Corte no puede soslayar al ponderar el quantum de los perjuicios que demanda, conforme lo previene el artículo 2330 del Código Civil"'68.

La jurisprudencia trasandina, por su parte, ha utilizado el criterio del consumidor medio para condenar al vendedor de un automóvil, en razón precisamente de la diligencia que se espera de él: "el comprador (...), actuando con la diligencia normal del hombre común (aquel que de tanto en tanto y de acuerdo a sus circunstancias, posibilidades y necesidades se acerca a una concesionaria o a un vendedor de automóviles, a adquirir un modelo nuevo y cambiarlo por el antiguo que poseía), debió confiar en esa apariencia y al ser ganado y actuar en consonancia con la misma, no estaba obligado a indagar la realidad subyacente y oculta tras ella para que podamos predicar de él su buena fe. Es que recibida la tradición del automotor adquirido y abonado su precio mediante la entrega de su usado y la suscripción de un contrato prendario a favor de la concesionaria, no podrá imputársele una falta de debida diligencia, fallas de previsión o de representación, ligereza o torpeza, por no saber, entender o advertir que el verdadero sujeto vendedor era otro" 69.

Por último, cabe mencionar un caso que la prensa nos dio a conocer en junio del año 2008: La empresa de artículos tecnológicos Dell ofreció en su página web institucional una serie de computadores portátiles a un cierto precio, el cual sufría una disminución considerable (menos del $50 \%$ del precio normal) cuando la plataforma tecnológica solicitaba su pago. Al percatarse de lo anterior, la empresa proveedora-argumentando que se había producido un error informático- emitió un comunicado, por el cual informaba que no respetaría las transacciones realizadas.

juguetes deberán ser diseñados y fabricados de forma que su ingestión, inhalación, contacto con la piel, las mucosas o los ojos, no represente riesgos para la salud o peligro de lesiones corporales cuando se utilicen de acuerdo a su destino normal conforme a su uso previsible por el comportamiento babitual de los niños".

67 "Espinoza con Grez Ulloa”, Rol 3944-2005, 1 JPL Chillán, 29.08.06.

68 “Sernac con Sodimac S.A.”, Ing. 9233-09, C. Ap. Santiago, 22.12.09, en relación a Rol 18.921-6-07, JPL Renca, 29.05.09, se declara inadmisible recurso de queja, Ing. 9693-09, C.S., 05.01.10.

${ }^{69}$ Dr. Roncoroni, sentencia "Park c. Galia S.A.", C 1 ${ }^{\circ}$ Civil y Comercial, La Plata, Sala III, 16/3/2000, en Stiglitz, Gabriel A., "Derecho del Consumidor", No 11, Editorial Juris, Rosario, 2000, p. 119. 
En este caso, uno de los aspectos discutidos en un nutrido intercambio de cartas y publicaciones en los periódicos nacionales dijo relación precisamente con la posición subjetiva del consumidor, esto es, si sabía que se trataba o no de un precio errado.

Al respecto, Guerrero Valenzuela y Prado Puga sostuvieron que no podía entenderse que tales transacciones fueran válidas, por cuanto en tal caso el ejercicio del derecho subjetivo por parte del consumidor estaría atentando en contra del principio Nemo auditur, el cual resultaría aplicable no sólo al error propio, sino que también al ajeno ${ }^{70}$. Agrega Guerrero, que el fundamento de la LPC -y por tanto el límite a las facultades que confiere- es proteger a los consumidores frente a abusos de proveedores, mas no para tutelarlos de sus propios abusos ${ }^{71}$.

En cualquier caso, cabe señalar que en supuestos como el señalado el criterio del consumidor medio puede ser útil para resolver si aquel abusó o no del derecho de adquirir un producto a un precio no superior al exhibido (Art. 18 LPC) $)^{72}$. En efecto, no es lo mismo aquel sujeto que adquirió un solo producto que aquel otro que habría comprado una docena. De la misma manera, deberá tratarse de manera diferente a aquel usuario que con frecuencia adquiere bienes por internet que aquel otro que lo realiza de manera esporádica.

La jurisprudencia por su parte, si bien en estos casos en general ha optado por liberar de responsabilidad al proveedor, lo ha realizado en razón del examen de la culpa de este último o bien a partir de las normas sobre formación del consentimiento, sin referirse a la posición subjetiva del consumidor ${ }^{73}$, perdiendo una importante oportunidad de pronunciarse sobre las limitaciones de los derechos de los consumidores.

Un caso de similares características - pero de una envergadura notablemente menorse había presentado ya en el año 2007 y fue fallado por la jurisprudencia haciendo alusión precisamente al abuso del derecho establecido en el mismo Art. 18 LPC: "Es lo cierto que dicha disposición no está contemplada para el caso de errores manifiestos, como el de autos, sino a conductas de mala fe por parte del proveedor del bien o el servicio, tendientes a engañar al consumidor en el precio de las cosas que ofrece para la venta. Y en la especie se trató, tantas veces lo hemos dicho, de un simple error de transcripción o de imprenta, oportunamente rectificado y publicada dicha rectificación, de modo que imponer una multa a La Dehesa Store Limitada y obligarla a vender al denunciante un bien cuyo verdadero precio es $\$ 2.600 .000$ en $\$ 899.000$, constituye un caso de abuso del derecho por parte de aquél que, en concepto del que disiente, no puede ser amparado por la judicatura"74.

\footnotetext{
${ }^{70}$ Diario El Mercurio de fecha 13.07.2008.

${ }^{71}$ Guerrero Valenzuela, Roberto, en Diario El Mercurio de fecha 13.07.2008.

${ }^{72}$ Art. 18 LPC: "Constituye infracción a las normas de la presente ley el cobro de un precio superior al exhibido, informado o publicitado".

73 “Sernac con Dell Computer Chile Ltda.”, Rol 771-5-2009, JPL Quinta Normal, 25.11.2009, confirmada por la C. Ap. Santiago, Ing. 1.646-2010, 04.08.2010; "Bascuñán Velasco con Dell Computer”, Rol C-27.382-08, 21 JL Civil de Santiago, 30.09.10. En sentido contrario se condenó a la empresa: "Sernac con Dell Computer Chile”, Rol 689-2007, JPL Pirque, 07.11.08, confirmada por C. Ap. San Miguel, Ing. 196-2009, 06.04.09.

74 “San Martín Camiruaga con La Dehesa Store Limitada (Ripley)”, C. Ap. Santiago, Voto de minoría de Juan Cristóbal Mera Muñoz, Rol 3721-2007, MJJ15385, 23.08.2007.
} 
b) Los deberes de los consumidores

Tal como se adelantó, el Art. 3, junto con consagrar los derechos básicos de los consumidores, establece ciertos deberes a los cuales el usuario debe sujetarse en el ejercicio de sus derechos.

El primero de ellos se encuentra consagrado en su literal b) y consiste en el deber de informarse responsablemente sobre los bienes y servicios, su precio, condiciones de contratación y otras características relevantes de los mismos. Se trata de una carga consagrada junto al derecho del consumidor a una información veraz y oportuna y por la cual se le exige al sujeto más débil de la relación de consumo un nivel de diligencia en la disminución de la asimetría de información que lo distancia del proveedor.

En este sentido, se ha negado la indemnización de perjuicios solicitada, argumentándose que el Art. 3 letra b) que "informa todo el sistema chileno de protección al consumidor, no se limita a imponer al proveedor la obligación de proporcionar la información del servicio prestado o los términos del contrato, sino que además requiere que el consumidor se preocupe de revisar la información entregada (...)"75.

En segundo término, nos encontramos con el deber del consumidor de evitar los riesgos que pudieren afectarle, establecido a propósito del derecho a la seguridad en el consumo de bienes o servicios, la protección de la salud y el medio ambiente (Art. 3 letra d). En este caso -y tal como se vio a propósito del uso razonable de productos y servicios- se condiciona el derecho a la inocuidad en el consumo, a que el usuario no se exponga al riesgo de manera culpable o dolosa, toda vez que en tal caso estará excediendo su prerrogativa.

Si bien nuestra jurisprudencia no ha reconocido este principio, es posible advertir en una sentencia de la Corte de Apelaciones de Santiago un interesante voto de minoría que estuvo por absolver a la empresa proveedora, en una causa sobre hurto de especies en un estacionamiento pagado, "por haber ésta acreditado suficientemente (...) de haber adoptado las medidas de seguridad suficiente para evitar elevar el riesgo para el consumidor más allá de lo permitido por el servicio de comercio que los vinculó, por lo que, no existe de su parte un 'servicio defectuoso' que sea la causa del resultado dañoso sufrido por el cliente, sino más bien, la fuente de ésta es la autopuesta en peligro por parte de la víctima, al dejar a la vista de terceros, sin cautela alguna las especies sustraídas" ${ }^{76}$.

En tercer lugar, encontramos el deber del consumidor de accionar de acuerdo a los medios que la ley le franquea, el cual se encuentra consagrado a propósito del derecho a la reparación e indemnización adecuada y oportuna de todos los daños materiales y morales en caso de incumplimiento de cualquiera de las obligaciones contraídas por el proveedor (Art. 3 letra e).

75 "Sernac con Viajes Falabella", Rol 1973-Dio-07, 3 JPL Santiago, 29.06.07, considerando 12, confirmada por la C. Ap. Santiago, Ing. 4096-07, 12.09.07

${ }^{76}$ Voto de minoría del Ministro Sr. Zepeda, recaído en "Sernac con Sociedad Concesionaria Plaza de la Ciudadanía”, C. Ap. Santiago, Ing. 2784-10, 03.11.10, que confirma la sentencia Rol 23616-Dio-08, 3 JPL Santiago, 25.05.10. 
De acuerdo a lo anterior, es que la tutela del interés resarcitorio del consumidor se extiende únicamente a aquellos casos en los cuales éste accionare de acuerdo a los procedimientos y demás normas adjetivas que el ordenamiento jurídico contemplare, utilizados de acuerdo a los fines para los cuales el legislador los estableció.

Así las cosas, se excederá de su derecho -y por tanto se le puede negar la indemnización solicitada- aquel que utilizare procedimientos inadecuados o recurriere ante tribunales incompetentes, a sabiendas, con el único objeto de obtener mayores condiciones procesales o sustantivas que las que le correspondieren, de acuerdo al espíritu de la LPC.

En este sentido, nuestra jurisprudencia civil ha reconocido también la posibilidad de que una acción judicial se ejerza de manera abusiva: "Las acciones y los recursos legales deben intentarse seriamente y existirá abuso de derecho cuando su titular lo ejerza culpablemente, sin la diligencia o cuidado que los hombres emplean ordinariamente en sus actos o negocias propios" 77.

El profesor Guerrero Becar, por su parte, estima que este deber dice relación en realidad con el ejercicio de los derechos, a través de los medios establecidos en la LPC, esto es, los reclamos interpuestos ante el Sernac y las acciones jurisdiccionales que señala el artículo $50 \mathrm{~B} \mathrm{LPDC}^{78}$.

Por último, se establece el deber de contratar con el comercio establecido (Art. 3 letra f), obligación que -según señala Fernández Fredes- fue introducida en nuestra legislación " $a$ instancias de los gremios de comerciantes, interesados en combatir por esta vía, entre otras, la competencia desleal que les significa el comercio informal o callejero" ${ }^{79}$. Si bien el legislador lo estableció a propósito del derecho a la educación para un consumo responsable, hubiese resultado más apropiado vincularlo con el derecho a compensación y resarcimiento, por cuanto este último naturalmente no concurrirá si se ha contratado con el comercio informal. Por tal razón, es que en este caso no se advierte una correlatividad con el derecho a la educación, el cual es de cargo del Estado y debe ser satisfecho en cualquier caso ${ }^{80}$.

\section{Limitaciones derivadas de los derechos ajenos: las garantías de los proveedores}

Corresponde ahora hacer una referencia a la segunda categoría de restricciones a las cuales se encuentra sujeto el ejercicio de los derechos subjetivos: aquellas derivadas de las garantías conferidas a los proveedores.

Al respecto, cabe señalar primeramente que los sujetos más poderosos de la relación de consumo se encuentran reconocidos expresamente por el Constituyente en el Art. 1 inc.

77 "Stjepovich González con Universidad de Antofagasta”, Rol 36.492-2001, 3 J.L. Antofagasta, 24.05.2002, confirmada por la C. Ap. de Antofagasta, 11.12.2002, se acoge recurso de casación, C.S., Ing. 228-2003, 09.11.2004.

${ }^{78}$ Cfr. Guerrero Becar, José Luis, op. cit., p. 192.

${ }^{79}$ Fernández Fredes, Francisco, "Manual de Derecho Chileno de Protección al Consumidor”, p. 18.

${ }^{80} \mathrm{La}$ educación para el consumo es un derecho recomendado por la OCDE y establecido como de cargo tanto de los Estados como de los proveedores: en "Recomendación del Consejo de la OCDE relativa a los lineamientos para la protección al consumidor en el contexto del comercio electrónico”, 09.12.1999, Disponible en http://browse.oecdbookshop.org/oecd/pdfs/free/9300024e.pdf, revisado el 09.05.2011, p. 9. 
$2^{\circ} \mathrm{CPR}$, al referirse a los "grupos intermedios", a quienes se les garantiza la adecuada autonomía para cumplir sus propios fines específicos. Se trata de una consagración que, ubicada en las propias Bases de la Institucionalidad, debe informar las normas siguientes de nuestra Carta Fundamental, y por ella, el resto de nuestro ordenamiento jurídico.

De la misma manera, a los proveedores les asisten las garantías para desarrollar cualquier actividad económica que no sea contraria a la moral, al orden público o a la seguridad nacional (Art. $19 \mathrm{~N}^{\circ} 16 \mathrm{CPR}$ ) y a la no discriminación en materia económica (Art. $\left.19 \mathrm{~N}^{\circ} 22 \mathrm{CPR}\right)$.

Ahora bien, lo anterior no significa en ningún caso que los derechos de los proveedores puedan ejercerse de manera absoluta, toda vez que ellos se encuentran igualmente limitados tanto por sus propias restricciones positivas (Art. $19 \mathrm{~N}^{\circ} 16 \mathrm{CPR}$ ) -entre las cuales se encuentra la misma Ley $\mathrm{N}^{\circ} 19.496$ y su normativa complementaria-, así como por los derechos de los consumidores ${ }^{81}$.

Desde este punto de vista, es que se ha sostenido que la tutela del usuario debe encontrarse además en sintonía con el sistema económico de que se trate. Al respecto advierte Jara, "siempre debemos considerar que dicha protección debe enmarcarse dentro del ordenamiento constitucional, y por lo tanto no podrá llegarse al extremo de, a pretexto de una protección excesiva, pretender violar principios constitucionales que establecen la libertad de desarrollar toda actividad empresarial, en cuanto ella se enmarque en los límites señalados por la propia Constitución. Ello significaría atentar contra el modelo económico impuesto por la Constitución, que no es otro que el de una economía de mercado" 82 .

En el mismo sentido opina Mosset: "El derecho del consumidor no puede desconocer que las relaciones económicas del mercado de producción, distribución y consumo, tienen un 'orden natural', una impronta que se orienta hacia la eficiencia, al lucro y la productividad"83.

Prueba de lo anterior radica en que tanto en nuestro país como en legislaciones comparadas la institucionalidad de protección de los derechos de los consumidores depende de manera directa de los Ministerios de Economía ${ }^{84}$ y no de los Ministerios de Justicia, como sería si únicamente se buscase la protección del más débil.

${ }^{81}$ Se debe tener presente, que no es lo mismo el abuso del derecho, que la colisión de derechos. En efecto, explica Rodríguez Grez, "El abuso del derecho no puede confundirse (...) con una colisión de derechos, pues, en tal sentido, la cuestión tiene otro alcance. El abuso del derecho supone un conflicto o colisión de intereses", en Rodríguez Grez, Pablo, op. cit., p. 137.

82 Jara Amigo, Rony, op. cit., p. 48.

${ }^{83}$ Mosset Iturraspe, Jorge, "Introducción al Derecho del Consumidor", en revista de Derecho Privado y Comunitario”, T. 5, Editorial Rubinzal Culzoni, Santa Fe, Argentina, 1996, p. 7.

${ }^{84}$ Art. 57 LPC: "El Servicio Nacional del Consumidor será un servicio público funcionalmente descentralizado $y$ desconcentrado territorialmente en todas las regiones del país, con personalidad jurídica y patrimonio propio, sujeto a la supervigilancia del Presidente de la República a través del Ministerio de Economía, Fomento y Reconstrucción". La misma situación se puede observar en el Derecho Comparado: En Italia: Consejo nacional del consumidor y del usuario (Consiglio Nazionale dei Consumatori e Utendi), dependiente del Ministerio de la Industria; En Argentina: Secretaría de Comercio Interior, dependiente del Ministerio de Economía y Producción; En Uruguay: Dirección del Área de Defensa del Consumidor, dependiente del Ministerio de Economía y Finanzas; en México: Procuraduría federal del consumidor, dependiente del Ministerio de Economía. 
Cabe señalar por último que en cualquier caso, en la materia que nos ocupa, tanto el legislador como el constituyente han optado por elevar el nivel de protección del usuario, en desmedro del proveedor, por considerarlo un sujeto más débil, de tal manera que el reconocimiento de los derechos del proveedor, en ningún caso, implica una merma de la interpretación pro consumatoris que debe inspirar la lectura y exégesis de las normas que los regulan ${ }^{85}$.

\section{EFECTOS DE LA VULNERACIÓN DE LOS LÍMITES O RESTRICCIONES DE LOS DERECHOS DE LOS CONSUMIDORES}

Una vez revisadas las restricciones a las cuales se encuentran sujetas las garantías de los consumidores, cabe mencionar los posibles efectos jurídicos a que puede dar lugar su vulneración.

Al respecto, cabe señalar primeramente que, conforme al Art. 50 E LPC ${ }^{86}$, aquella denuncia, querella o demanda interpuesta en contra de un proveedor, que carezca de fundamento plausible -como sería la acción de un consumidor que ha abusado de su derecho-, puede ser declarada temeraria. La sanción en este caso se traducirá en una multa infraccional para el actor temerario, la que puede llegar incluso a las 200 UTM si este último se encuentra contemplado en el Art. $51 \mathrm{~N}^{\circ} 1$ LPC.

La inclusión de la disposición señalada en la Ley $\mathrm{N}^{\circ} 19.496$, ya en su fase de discusión, se la consideró como una sanción al ejercicio ilegítimo de un derecho, tal como se advierte en la siguiente observación presidencial: "También se plantea una sanción para aquel consumidor que, a raíz del ejercicio abusivo del derecho a ejercer las acciones que consagra el proyecto en referencia, sea declarado temerario en su denuncia por el tribunal competente" 87 .

No obstante lo anterior, y tal como lo advierte Guerrero, si bien el Art. 50 E LPC contribuye a proteger al proveedor frente a eventuales abusos de los consumidores, dicha norma presenta la dificultad de que exige como requisito de procedencia que el usuario previamente haya interpuesto una denuncia, demanda o querella anterior ${ }^{88}$. En otras palabras, sólo sanciona el ejercicio abusivo de una acción judicial, mas no otras formas que pueda revestir la institución en estudio.

${ }^{85}$ Cfr. Jara Amigo, Rony, op. cit., p. 48

86 "Cuando la denuncia, querella o demanda interpuesta carezca de fundamento plausible, el juez, en la sentencia y a petición de parte, podrá declararla como temeraria. Realizada tal declaración, los responsables serán sancionados en la forma que señala el artículo 24 de esta ley, salvo que se trate de acciones iniciadas de conformidad a lo señalado en el $N^{o} 1$ del artículo 51. En este último caso, la multa podrá ascender hasta 200 unidades tributarias mensuales, pudiendo el juez, además, sancionar al abogado, conforme a las facultades disciplinarias contenidas en los artículos 530 y siguientes del Código Orgánico de Tribunales./ Lo dispuesto en el inciso anterior se entenderá sin perjuicio de las responsabilidades penal y civil solidarias de los autores por los daños que bubieren producido".

87 Veto Presidencial, Oficio del Ejecutivo a Cámara de Origen, 15.10.1996, Cuenta en sesión 7, Legislatura 334, Observación $\mathrm{N}^{\circ} 5$.

${ }^{88}$ Cfr. Guerrero Becar, José Luis, op. cit., p. 206. 
Otro efecto jurídico que podría configurarse sería naturalmente la indemnización de perjuicios. En este sentido, se debe recordar que el mismo Art. 50 E LPC establece que la sanción infraccional por denuncia temeraria se entiende sin perjuicio de la responsabilidad civil y penal que pudiera corresponder.

Ahora bien, la acción de resarcimiento por el ejercicio abusivo de un derecho distinto del contemplado en dicha norma se encontrará sujeta a las normas del Derecho Común.

Así las cosas, se puede observar que las consecuencias jurídicas del abuso del derecho en estas materias son variadas, pudiendo observarse que en la práctica nuestra jurisprudencia mayoritaria se ha limitado a absolver al proveedor de una eventual condena infraccional o civil.

De acuerdo a lo anterior -y a la disímil naturaleza de las sanciones a las que puede dar origen la institución en estudio-, es que resulta más apropiada para explicar este fenómeno en la materia que se estudia la teoría que la entiende como un principio general del derecho, toda vez que no restringe el efecto jurídico que pudiere dar lugar a la acción de resarcimiento.

Ahora bien, y respecto del procedimiento aplicable, el profesor Guerrero Becar sostiene que en caso de contravenciones imputables a los propios consumidores la Ley $\mathrm{N}^{\circ} 19.496$ no contempla una acción especial que proteja los derechos de los proveedores perjudicados, razón por la cual se verán en la necesidad de recurrir a la justicia civil ordinaria.

En estos casos, afirma, "nos encontraremos con el becho de no existir una acción tutelar en el marco del propio Derecho especial del consumidor que permita al proveedor ejercitar sus pretensiones en contra del o los consumidores que han afectado sus derechos, de manera que el proveedor queda fuera de la protección mínima de la legislación especial de consumo y entregado, consecuentemente, al Derecho común, en que deberá accionar conforme con las acciones procesales ordinarias, como si no existiera un Derecho especial del consumidor"89.

\section{Conclusiones finales}

i. Dos han sido las tesis que en nuestra tradición jurídica han intentado explicar la naturaleza del abuso del derecho, a saber: entenderlo como una fuente de responsabilidad extracontractual o concebirlo como un principio general del derecho. En materia de consumo, es la segunda la que explica de mejor manera tanto la naturaleza de las prerrogativas involucradas como el efecto jurídico de su ejercicio abusivo.

ii. En lo que dice relación con la naturaleza jurídica de los derechos de los consumidores, es posible concebirlos como derechos subjetivos, sin perjuicio de que la tesis romana de la posición justa resulta más adecuada para explicar los deberes que ellos implican.

${ }^{89}$ Guerrero Becar, José Luis, op. cit., p. 190. 
iii. De las normas positivas que regulan las relaciones de consumo, es posible advertir ciertas limitaciones que restringen la protección del consumidor, entre las cuales se encuentran las siguientes: la protección del consumidor medio, los deberes de los usuarios y el respeto de los derechos de los proveedores.

iv. El efecto jurídico que produce el ejercicio abusivo de los derechos de los consumidores no se restringe a la indemnización de perjuicios, sino que en general ha devenido en la absolución del proveedor.

v. La Ley $\mathrm{N}^{\circ} 19.496$ establece un efecto particular del ejercicio abusivo de una acción judicial, cual es la declaración de la temeridad de la acción.

\section{BIBLIOGRAFÍA}

\section{i. Normativa}

\section{i.i. Normativa Nacional}

Constitución Política de la República, 1980.

Código Civil.

Código de Procedimiento Civil.

Código de Comercio.

Ley $\mathrm{N}^{\circ} 19.496$.

Ley General de Bancos.

Ley de Sociedades Anónimas.

Ley de Copropiedad Inmobiliaria.

Ley de Quiebras.

Decreto 114/2005/MinSal, Reglamento sobre seguridad de los juguetes.

\section{i.ii. Normativa Comparada}

Constitución Política de Colombia.

Código Civil de Perú.

Código Civil de España.

Código Civil de Suiza.

Código Civil de Colombia.

Código Civil de Paraguay.

Código Civil de Portugal.

Código Civil de México.

Código Civil de Alemania (BGB).

Código Civil de Venezuela.

Directiva de Seguridad de Productos, 2001/95/CE.

Directiva sobre Prácticas Comerciales Desleales en sus relaciones con Consumidores, 2005/29/CE.

Estatuto del Consumidor, Decreto 3466, Colombia.

Ley de Protección de los Consumidores, Perú, DS 006-2009 PCM.

Ley de Defensa del Consumidor, Argentina, No 24.240.

Ley de Protección del Consumidor y Defensa de la Competencia, Panamá, No 45/2007. 
Ley Federal de Protección del Consumidor, México.

Ley General de Defensa de los Consumidores y Usuarios, España.

ii. Doctrina

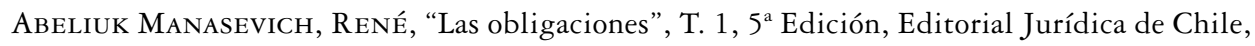
Santiago, 2008.

Alcalde Rodríguez, Enrique, "Corte de Apelaciones de Santiago y Teoría de la imprevisión. Un hito fundamental en la evolución de nuestra justicia ordinaria", en Revista Chilena de Derecho, Vol. $34 \mathrm{~N}^{\circ}$ 2, Santiago, 2007.

Alessandri Rodríguez, Arturo, "De la responsabilidad extracontractual en el Derecho Civil Chileno”, Imprenta Universitaria, Santiago, 1943.

Barros, Enrique, "Tratado de responsabilidad extracontractual”, Editorial Jurídica de Chile, Santiago, 2007.

Borda A., Guillermo, Prólogo, en Fernández Sessarego, Carlos, "Abuso del derecho", Editorial Astrea, Buenos Aires, 1992.

Candian, Aurelio, "Instituciones de Derecho Privado", Unión Tipográfica Hispano Americana, México, 1961.

Chapman, Charles, "El abuso del derecho de asociación en la creación de sindicatos", en Revista de Derecho, Universidad del Norte, $\mathrm{N}^{\circ}$ 22, Colombia, 2004.

Cuneo Macchiavello, Andrés, "Copropiedad inmobiliaria y propiedad común”, en GuZmán Brito, Alejandro, Editor, "El Código Civil de Chile (1855-2005), Editorial LegalPublishing, Santiago, 2009.

Demsetz, Harold, "Hacia una teoría de los Derechos de Propiedad", traducido de American Economic Review, mayo 1967.

Domínguez Águila, Ramón, "Fraus Omnia Corrumpit: Notas Sobre el Fraude en el Derecho Civil”, RDJ. LXXXIX. N 3.1992, MJD57.

Engel, Eduardo, "Protección a los consumidores en Chile. ¿Por qué tan poco y tan tarde?", en Revista Perspectivas en Política, Economía y Gestión, Vol. 1 No 2, 1998, Universidad de Chile.

Enneccerus, Ludwig, "Derecho Civil. Parte General”, Vol. 1, Bosch Publicaciones Jurídicas, Buenos Aires, 1948.

Fernández Cruz, Gastón, "Las transformaciones funcionales de la responsabilidad civil: La óptica sistémica”, en Revista de la Facultad de Derecho, Universidad Nacional de San Agustín de Arequipa.

Fernández Fredes, Francisco, "La protección jurídica de la calidad", en Pizarro Wilson, Carlos, Editor, "Temas de Derecho del Consumidor", Cuadernos de análisis jurídico, Ediciones Universidad Diego Portales, Servicio Nacional del Consumidor, Santiago, 1997.

Fernández Fredes, Francisco, "Nueva Ley del Consumidor: innovaciones y limitaciones”, en Revista Perspectivas en Política, Economía y Gestión, Facultad de Ingeniería y Ciencias Universidad de Chile, Vol 1 No 2, 1998, Santiago.

Fernández Fredes, Francisco, "Manual de Derecho Chileno de Protección al Consumidor", Editorial LexisNexis, Santiago, 2003.

Fernández Sessarego, Carlos, “Abuso del derecho”, Editorial Astrea, Buenos Aires, 1992.

Fuentes, Fernando y SaAvedra, Eduardo, "Análisis de Tres Elementos de la Ejecución de la Política de Protección al Consumidor, con Énfasis en la Comparación con las Mejores Prácticas de otros Países", Ministerio de Economía, 2009, disponible en http://www.economia.cl/1540/articles-189395_recurso_1.pdf, revisado el 20.09.10. 
Fueyo Laneri, Fernando, "El ejercicio abusivo del derecho", en Revista del Colegio de Abogados, La Plata, 1988.

Fueyo Laneri, Fernando, "El Fraude a la ley", RDJ. LXXXVIII. No 2.1991, MJD41.

Gatti, Edmundo, "Comentarios al "Proyecto de Código Civil", en Revista Verbae Iustitia, Vol. $7, \mathrm{~N}^{\circ} 12$.

Guerrero Becar, José Luis, "La acción temeraria en la Ley No 19.496 sobre Protección de los Derechos del Consumidor”, en Revista de Derecho, Pontificia Universidad Católica de Valparaíso, Valparaíso, 2008.

Guzmán Brito, Alejandro, "Para la historia del derecho subjetivo", en Revista Chilena de Derecho, Pontificia Universidad Católica de Chile, Vol. 2, Santiago, 1975.

Guzmán Brito, Alejandro, "Historia de la denominación del derecho-facultad como 'subjetivo’”, en Revista de Estudios Histórico-Jurídicos, Vol. XXV, Valparaíso, 2003.

Jara Amigo, Rony, "Ámbito de aplicación de la Ley chilena de protección al consumidor: inclusiones y exclusiones", en Corral Talciani, Editor, "Derecho del consumo y protección al consumidor", Cuadernos de Extensión No 3, Facultad de Derecho, Universidad de los Andes, Santiago, 1999.

Lira Urquieta, Pedro, "El Código Civil Chileno y su época”, Editorial Jurídica de Chile, Santiago, 1956.

Loewenwarter, Víctor, "Consultorio Jurídico. A través de la jurisprudencia moderna de la Corte Suprema y de los Tribunales Superiores sobre cuestiones de Derecho Civil y Comercial”, Ediciones de la Universidad de Chile, 1937.

Momberg Uribe, Rodrigo, “Ámbito de Aplicación de la Ley Nº 19.496 sobre Protección de los Derechos de los Consumidores”, en Revista de Derecho, Universidad Austral de Chile, Vol. XVII, Valdivia, diciembre 2004.

Mosset Iturraspe, Jorge, "Introducción al Derecho del Consumidor", en revista de Derecho Privado y Comunitario, T. 5, Editorial Rubinzal Culzoni, Santa Fe, Argentina, 1996.

Rodríguez Grez, Pablo, "El Abuso del Derecho y el Abuso Circunstancial”, Editorial Jurídica de Chile, Santiago, 2004.

Santos Ballesteros, Jorge, "El abuso del derecho”, Editorial Universidad Javeriana, Bogotá, Colombia, 1973.

Stiglitz, Gabriel y Gandolfo de Stiglitz, Ana Claudia, "Responsabilidad estricta del industrial por daños al consumidor", en "Derecho del Consumidor", N 7, Editorial Juris, Rosario, 1996.

TAPia R., MAuricio, "El contrato de seguro y el exceso de responsabilidad civil”, en Revista del Magíster y Doctorado en Derecho, No 1, 2007, Facultad de Derecho Universidad de Chile.

Terrazas Ponce, Juan David, "Abuso del derecho. Definiciones en torno a su origen”, en "Estudios de Derecho Privado. Libro Homenaje al jurista René Abeliuk Manasevich", Editorial Jurídica de Chile, Santiago, 2010.

iii. Otros recursos

Registro público de sentencias de consumo, disponible en www.sernac.cl

Base de datos LegalPublishing.

Base de datos Microjuris.

Columnas de opinión de Guerrero Valenzuela, Roberto y Prado Puga, Arturo en Diario El Mercurio de fecha 13.07.2008.

Diccionario de la Lengua Española, en www.rae.es 
Directrices de las Naciones Unidas para la protección del consumidor, ampliadas en 1999, III.11, disponible en http://www.un.org/esa/sustdev/publications/consumption_sp.pdf, revisado el 09.05.2011.

OCDE. "Recomendación del Consejo de la OCDE relativa a los lineamientos para la protección al consumidor en el contexto del comercio electrónico", 09.12.1999, Disponible en http:// browse.oecdbookshop.org/oecd/pdfs/free/9300024e.pdf, revisado el 09.05.2011.

OCDE. "Recomendación de la OCDE sobre Resolución de Disputas y Resarcimiento a los Consumidores", 12.07.07, disponible en http://www.oecd.org/dataoecd/3/36/40060255. pdf, revisado el 09.05.2011. 
